\title{
The inalienability pattern of English and Norwegian
}

\author{
Martha Thunes ${ }^{{ }^{*}}$ \\ ${ }^{1}$ University of Bergen
}

\begin{abstract}
With reference to the language pair English-Norwegian, the present paper discusses nominal phrases referring to so-called inalienable possessions. In such cases, the relation of possession is typically expressed through obligatory possessor marking in English, and through possessor suppression in Norwegian, i.e., whereas the use of possessive determiners is obligatory in English, the semantic property of inalienabilty is in Norwegian expressed by definite form and no possessive. Exampes illustrating this translational pattern will be presented, and some corpus data will be considered. This will support a prototypical view of what classes of nouns fall within the pattern. Since there is a systematic difference in inalienability marking between English and Norwegian, it will be argued that the translation of noun phrases referring to inalienables is predictable within this language pair, because it is derivable from information about the two language systems.
\end{abstract}

Keywords: contrastive grammar; possession; inalienability marking; English-Norwegian translation; translational complexity

1 February 2013, second version

\footnotetext{
* Principal contact:

Martha Thunes, Researcher

Department of Linguistic, Literary and Aesthetic Studies, University of Bergen, Norway

Tel.: +4755583309

E-mail: martha.thunes@lle.uib.no
} 


\section{Introduction}

The present paper is based on a discussion given in Thunes (2011) of a systematic difference between English and Norwegian in the use of determiners in definite noun phrases referring to objects of possession. The contrast appears in certain translational correspondences between English NPs with possessive determiners and Norwegian definite NPs with no overt possessive; cf. the italicised phrases in example (1).

(1a) Hun løftet haken. ${ }^{1}$

'She raised chin.DEF.'

(1b) She raised her chin.

Example (1) illustrates what appears to be a relatively fixed translational pattern in this language pair, which primarily involves expressions referring to so-called inalienable possessions. Possessives can be described as a subcategory of determiners. Their primary syntactic function is to premodify nouns; and their semantic contribution is to specify the reference of the noun phrases in which they occur, and to encode a relation of possession. ${ }^{2}$ In the Norwegian sentence (1a) it is understood that the subject referent is the possessor of the object referent; this is expressed by the definite form of haken. Lødrup (2010: 92) provides an account for this through the generalisation that "[b]ody-part nouns usually require a possessor to be syntactically realised when they denote actual parts of a body..."3 Thus, in sentence (1a) the possessor is expressed by the syntactic subject, and, according to Lødrup's analysis, the definite noun phrase haken has an implicit possessive (2010: 92). In the English sentence (1b), on the other hand, the possessor relation is explicitly expressed by the possessive determiner her. The structure of (1b) is accounted for by the observation made by Dahl and KoptjevskajaTamm (2001: 211) that possessive determiners are obligatory in English in the case of "subjectcontrolled body part terms."

This article will start by discussing possession and inalienability, as well as kinship and body part terms. Then the inalienability pattern of English and Norwegian will be described and illustrated, and related to translational complexity as defined by Thunes (2011). Various occurrences of the pattern will be discussed, in order to support a prototype view of the phenomenon.

\section{Theoretical background}

\subsection{Possession}

It is relevant to consider the general notion of 'possession'. Heine (1997: 1) describes the concept of 'possession' as "inherently vague or fuzzy", and the set of relations that can be expressed by possessive constructions is quite heterogeneous (cf. Heine 1997: 2). McGregor (2009b: 1) demonstrates this heterogeneity by describing possession as:

... a relational concept that potentially covers a wide range of conceptual relations between entities, including, for human beings, between persons and their body parts and products, between persons and their kin, between persons and their representations (e.g. names, photographs), between persons and their material belongings (animate and inanimate items they own), between persons and things that they have usership-rights to

\footnotetext{
1 This example is found in Vik (1979/1983).

${ }^{2}$ Cf. Faarlund et al. (1997: 23); Quirk et al. (1985: 253-256).

${ }^{3}$ Lødrup points out two exceptions to this: body parts as "cut-off objects for anatomical study", and body part terms used with generic reference (2010: 92).
} 
or control over, between persons and cultural and intellectual objects, and so on. For other animates and inanimates a more restricted range of conceptual relations is generally available.

Various contributions have identified a range of types of possession, and through different descriptive approaches. ${ }^{4}$ Heine (1997: 5), as well as Herslund and Baron (2001: 2), point out that most researchers have a prototypical view of this phenomenon, in that some types of possession are regarded as more central instances than others. Citing Heine (1997: 39-41), Herslund and Baron (2001: 2) list the properties of prototypical possession "... such as "human possessor, concrete possessee, possessor having the right to use the possessee, spatial proximity between the two, no temporal limit on the possessive relation'." It is not easy to try to define what the different types of possession have in common, but at least, possession involves a relation between two entities, and it is always clear which of them is the possessor and which is the possessee (cf. Heine 1997: 2). In this very general sense, possession can be seen as a kind of part-whole relation.

\subsection{Inalienability}

In a non-technical understanding of the word inalienable, it can be read as the quality of being something that cannot be taken away from a person. The grammatical notion of 'inalienability', on the other hand, is ascribed to Lévy-Bruhl (1914), who discussed possessive constructions in Melanesian languages. According to Chappell and McGregor (1996b: 3), Lévy-Bruhl (1914: 9798) observed that in these languages, nouns could be divided into two classes due to two different kinds of morphological possession marking. The inalienable class of nouns comprised terms for kinship, body parts, spatial relations, and certain important personal belongings, whereas all other nouns were included in the alienable class. Chappell and McGregor (1996b: 3) note that "... this dichotomy represents a basic semantic pattern that recurs across many languages, regardless of genetic affiliation or grammatical type."

However, there is considerable variation across languages with respect to which nouns are classified, respectively, as alienable or inalienable, and culture-specific, as well as pragmatic, factors determine where the division is drawn in individual languages (cf. Chappell and McGregor 1996b: 9, Heine 1997: 11-12). Moreover, there are several languages where certain nouns may be used either as inalienable or as alienable (cf. Chappell and McGregor 1996b: 3). Such facts indicate that it is not always straightforward to predict, on the basis of the meaning of a given noun, whether it is inalienable or not. Heine (1997: 17-18) argues that inalienability is not merely a lexical property; it is rather an aspect of the relation between the possessor and the possessee, and one that has structural consequences reaching outside the noun phrase itself. Some researchers regard the alienability distinction as a type of noun classification similar to grammatical gender marking, but there is not general agreement on this point (cf. Heine 1997: 15-16). In a typological perspective, inalienability is a grammatical notion with semantic content, and its effects are visible on the levels of morphology as well as those of phrasal and clausal syntax.

\subsection{Kinship and body part terms}

Thus, it does not seem correct to treat inalienability merely as a lexical property. Still, in the following we shall consider some examples of nouns denoting inalienable possessions, and, in general, the semantic classes of nouns that typically exhibit the property of inalienability, are kinship and body part terms. Applying a language-typological perspective, e.g. Dahl and Koptjevskaja-Tamm (2001: 208) observe that "[i]t is a well-known fact that kin[ship] terms and body part terms ... are the two semantic classes that are most often treated as "inalienable"

\footnotetext{
${ }^{4}$ Heine (1997: 2-6, 33-41) presents several approaches, and different types of possession. Also, Seiler (2001: 27) lists several studies on possession.
} 
whenever alienability distinctions are made." Example (1) in section 1 is a case of body part possession, and example (2) illustrates the class of kinship terms.

$$
\begin{aligned}
& \text { Jason spør moren. } \\
& \text { 'Jason asks mother.DEF.' } \\
& \text { Jason asks his mother. }
\end{aligned}
$$

\subsection{The inalienability pattern}

Seiler (2001: 28) makes the point that languages vary with respect to how inalienability is expressed. In relation to the language pair English-Norwegian, the two most relevant types of encoding are, respectively, obligatory possessor marking and possessor suppression. Both are illustrated by examples (1)-(2), which are taken from English-Norwegian parallel texts. Norwegian follows the strategy of possessor suppression, in which noun phrases referring to inalienable possessions have definite form and contain no possessive determiner, as shown by the NPs moren ('the mother') in (2a), and haken ('the chin') in (1a). ${ }^{6}$ This is quite the opposite of the English strategy, which is obligatory possessor marking, shown by the NPs his mother in (2b), and her chin in (1b). The translational correspondences holding within these pairs of noun phrases in (1) and (2) illustrate a regularity specific to this language pair, and are described by Thunes (2011: 363) as the inalienability pattern. Its canonical instances involve nouns denoting kinship and body parts, typically with human possessors, and, as shown, it is realised in English through obligatory possessor marking, and in Norwegian through possessor suppression. This cross-linguistic pattern will be further discussed in sections 3.1-3.

\subsection{Linguistic predictability in the translational relation}

The regularity of the inalienability pattern is interesting in relation to the task of translating between these two languages, and especially to the topic of automatic translation, or machine translation (MT). In modern MT, which is based on statististical techniques (SMT), translations are computed on the basis of statistical information about existing translational correspondences in large bodies of parallel texts. ${ }^{7}$ Thus, the systematic correspondences exhibited by the inalienability pattern are in principle detectable for the purposes of statistical MT, although it is an open question how large amounts of English-Norwegian parallel texts that would be required in order to predict target texts conforming to the pattern. There now seems to be a consensus that since there is a limit on how far SMT can reach in terms of translation quality, it is necessary to combine such techniques with methods that exploit linguistic information, and this renews the relevance of the classic approach to MT, so-called rule-based machine translation (RBMT), where the translation procedure relies on information about source and target languages and their interrelations.

Assuming the paradigm of RBMT, a notion of linguistic predictability in the translational relation is explicated by Thunes (2011: 69-75), following Dyvik (1998), (1999). This notion is based on the assumption that the relation between a given source text and its translation is predictable insofar as the source text together with a pre-structured domain of information can provide all the information needed to produce the target text. A further assumption is that this domain is restricted to information about source and target language systems and about how the two language systems are translationally related (cf. Thunes 2011: 70-72). Thus, if a certain target expression is a linguistically predictable translation of a given source expression, then it can be predicted as one of possibly several alternative translations, and the basis for predicting it is the linguistic information coded in the source text, together with given, general information

\footnotetext{
5 This example is found in Fosnes Hansen (1990/1996).

${ }^{6}$ Possessor suppression is also illustrated by the NP ryggsekken in the Norwegian sentence (4b) in section 3.3.

${ }^{7}$ See Jurafsky and Martin (2009: 898).
} 
about the two languages and their interrelations. Moreover, within this approach, computable translations are regarded as synonymous with linguistically predictable ones, and noncomputable translations are not linguistically predictable because non-computable translation tasks also require access to information sources lying outside the pre-structured domain of linguistic information sources (cf. Thunes 2011: 75). ${ }^{8}$

In this article it will be argued that since the different constructions used for expressing inalienability in English and Norwegian respectively are parts of the two language systems, translational correspondences between such expressions are linguistically predictable. Assuming a rule-based approach to MT, this means that translational correspondences instantiating the English-Norwegian inalienability pattern may represent computable translation tasks.

\section{Observations and discussion}

\subsection{A type of translation divergence}

Thunes (2011: 370-372) presents some data on occurrences of the inalienability pattern in a selection of English-Norwegian parallel texts. The principal topic of that study is not inalienability marking, but a notion of 'translational complexity', defined on the basis of certain assumptions concerning a translator's need for information when producing a given target text. To be more specific, translational complexity is analysed in terms of the types and amount of information needed in order to solve a specific translation task, as well as the effort required by accessing and processing that information. ${ }^{9}$ In Thunes (2011) translational complexity is studied in a selection of English-Norwegian parallel texts in order to investigate, firstly, to what extent the manually created target texts of that corpus could have been translated automatically, i.e. computed, within the rule-based approach, and, secondly, to find out whether the potential for automatisation varies between the two text types law and fiction, which are included in the material. In order to answer these research questions, the automatisation issue is tied to the notion of linguistic predictability. As explained in section 2.5 , the assumption is that linguistically predictable translations are computable.

The translational data studied in Thunes (2011) are a set of string pairs, primarily sentence-level units, extracted manually from various English-Norwegian parallel texts. The empirical method of the study aims to measure the degree of translational complexity in each recorded string pair, and this requires a thorough linguistic analysis carried out by a bilingually competent human. Hence the compiled data set is of a modest size: it covers merely 68000 words. On the other hand, the analysis has been deep enough to reveal a range of recurrent phenomena, which may be described as translation divergences, or mismatches, within the data. ${ }^{10}$ Included among these observations are 54 occurrences of the English-Norwegian inalienability pattern (cf. Thunes 2011: 371). The overall majority of these data are extracted from a selection of fiction texts (Brink 1984, Fosnes Hansen 1990/1996, Lessing 1985, Vik 1979/1983) included in the English-Norwegian Parallel Corpus (ENPC), which is documented in Johansson (1998, 2007), Johansson et al. (1999/2002), Hofland and Johansson (1998).

As explained by Thunes (2012: 84), Barnett et al. (1991) make a distinction between 'divergences' and 'mismatches' which is useful in relation to the notion of linguistically predictable translation. Following Dorr (1990), they describe translation divergences as cases

\footnotetext{
${ }^{8}$ In addition to information contained in the source expression and given by the pre-structured linguistic domain, solving a non-computable, or non-predictable translation task, may require information types such as extralinguistic world information, or information about the discourse context of the source expression.

${ }^{9}$ For a discussion of 'translational complexity', cf. chapter 3 in Thunes (2011).

10 These phenomena are discussed in chapter 6 of Thunes (2011).
} 
where "the same information is conveyed in the source and target texts, but the structures of the sentences are different" (Barnett et al. 1991: 25). Then, referring to Kameyama et al. (1991), they say that translation mismatches "occur when there are actually differences in the information that is conveyed" (Barnett et al. 1991: 25). Thus, if 'same information' can here be understood as the information that is linguistically encoded in a source expression and its corresponding target, then translation divergences fall within the domain of computable, or linguistically predictable translation, whereas mismatches represent non-computable, or linguistically non-predictable, translation. The examples discussed in this article will show that occurrences of the inalienability pattern in translational correspondences of English and Norwegian can be viewed as translation divergences, because they are predictable from information about the two language systems and about how they are translationally interrelated.

\subsection{A prototype view}

The 54 occurrences of the inalienability pattern studied in Thunes (2011) invite a prototype view of this phenomenon, and the characteristic properties of the canonical cases pertain to surface form as well as to semantic content. Concerning their formal aspects, it was observed in section 2.4 that in this pattern a possessive determiner is obligatory in the English noun phrase, whereas the Norwegian noun phrase is typically in the definite form, or, in the view of Lødrup (2010), it has an implicit possessive. With respect to the semantic properties, the core cases involve a human possessor and a so-called inalienable possessee (i.e. object of possession). In the occurrences reported on by Thunes (2011), human possessors are dominating and prototypical, as the possessor is a human in 50 out of 54 recorded instances $(92,6 \%)$. In two of the deviating cases, which are found in a pair of law texts, ${ }^{11}$ the possessor is a kind of institution, and in the other two, which are found among data extracted from fiction, the possessor is an inanimate object. In three of the four deviating cases, the encoded relations of possession are kinds of part-whole relations, as illustrated by the noun phrase its strap in example (4) in section 3.3. (See Thunes 2011: 360-361.)

As made clear in sections 2.1 and 2.2, it is common that language researchers adopt prototypical views of the phenomena of possession and inalienability, and typological research also provides support for a prototype account of the English-Norwegian inalienability pattern. Based on empirical investigations, different linguists have tried to establish alienability scales, or hierarchies where the most prototypically inalienable class(es) of nouns are at the top of the scale, and gradually less typical classes follow below. ${ }^{12}$ The tendency is that the central kinds of inalienable constructions are linked to kinship, body parts, part-whole and spatial relations, but, as Chappell and McGregor (1996b: 8-9) point out, languages vary so much with respect to the organisation of such hierarchies that a universal scale cannot be assumed.

Kinship and body part terms are the two most important classes of nouns that appear in the canonical instances of the inalienability pattern studied by Thunes (2011). With respect to the 54 cases of the inalienability pattern discussed by Thunes (2011), 34 of them involve prototypical kinds of inalienable possessions $(63,0 \%)$. Among the prototypical cases there are, in addition to kinship and body part terms, a few nouns denoting concepts such as 'mind', 'life', and 'voice', which are, like kinship and body parts, non-transferrable properties of the possessor; cf. example (3):

His voice was curt, ... ${ }^{13}$

Stemmen var knapp, ...

\footnotetext{
11 The Agreement on the European Economic Area, and its parallel Norwegian version.

${ }^{12}$ Cf. Chappell and McGregor (1996b: 8-9).

13 This example is found in Lessing (1985).
} 
To treat (3) as a canonical case is in line with the position taken in Lødrup (2010). His study concerns implicit possessives used with body part terms in Norwegian, and among the questions he addresses is whether the use of implicit possessives can be extended to non-body part terms in Norwegian. He mentions concepts such as 'hearing' and 'memory' as examples of nouns that also may take implicit possessives (Lødrup 2010: 99). It is reasonable that this holds also for English, since these two languages are not very distant from each other, neither typologically nor culturally.

It should be noted that while kinship terms are here included among the core instances of the English-Norwegian inalienability pattern, Lødrup (2010: 99) does not find this class of nouns to be of central relevance in his study of implicit possessives. Moreover, it is interesting that Dahl and Koptjevskaja-Tamm (1998), when discussing kinship and body part terms in a typological perspective, report that the two categories differ with respect to the way in which the possessor (or the anchor) is identifiable, and they claim that kinship terms are "pragmatically anchored", while body part terms are "syntactically anchored" (1998: 43-44). This means that in the case of body part terms, the use of inalienability marking is dictated by the language system, whereas in the case of kinship terms it is also determined by factors pertaining to language use. Thunes (2011: 364) suggests that the English-Norwegian inalienability pattern is possibly more of a linguistic regularity in the case of body part terms than in the case of kinship terms, but the analysed data are too few to decide this question. Since Dahl and Koptjevskaja-Tamm (1998: 44) state that "[i]n both cases, we are dealing with highly predictable possessors", it seems reasonable to include both classes of nouns in the prototypical kernel of the pattern.

\subsection{Non-canonical cases}

With respect to the non-canonical occurrences of the English-Norwegian inalienability pattern, Thunes (2011: 364-365) reports that the nouns occurring in the less prototypical instances denote concepts tentatively grouped into (i) clothes, parts of garments, and other things attached to the body (e.g. jacket, inside pocket, make-up), (ii) other objects used by humans (e.g. backpack, book, cigarette, instrument, tea cup), and (iii) human activities (e.g. exercises, work). Moreover, the nouns observed within these three groups have in common that they may occur with inalienability marking when they are associated with only one possessor (i.e. user, or agent) at a time, because there is some kind of close connection, such as physical contact, between the unique anchor and the possessee. Also, the connection in question is normally required for typical use of the possessed object. In contexts where these nouns do not carry inalienability marking, the criterion of a close connection tends to be absent. Within the recorded data, these facts seem to apply in both of the investigated languages, but the empirical material is too limited to conclude that there is full correspondence between English and Norwegian on this point.

The generalisation across the three groups of concepts is in line with observations made by Lødrup (2010: 99-100) regarding extensions of the use of implicit possessives to certain nonbody part terms in Norwegian. The generalisation is also supported by typological studies of alienability splits in connection with clothing and related notions: in several languages inalienability marking occurs in possessive constructions referring to clothes and similar objects that are worn, whereas the same objects are treated as alienable possessions when they are not attached to a person's body (cf. Heine 1997: 17-18). There seems to be general agreement that the use of inalienability marking is, in culture-specific ways, extended to various classes of nouns that may be included in what Bally (1996/1926) described as "the personal domain". 
Two examples may illustrate non-canonical occurrences of the English-Norwegian inalienability pattern. Example (4) contains two pairs of translationally corresponding noun phrases that conform with the pattern but are non-canonical instances:

She dragged her backpack by its strap after her ...14

Hun dro ryggsekken med seg etter skulderremmen ...

'She dragged backpack.DEF with self after shoulder-strap.DEF.'

The four noun phrases her backpack, its strap, ryggsekken and skulderremmen in (4) have in common that they refer uniquely to specific entities. In the cases of the English NPs, unique reference is expressed through the possessives her and its, and in the Norwegian phrases through the suffix -en, which is a marker of definite form. ${ }^{15}$ Compared with the definite markers in the Norwegian NPs, the English possessives her and its provide a larger amount of information since they not only specify the reference of the NPs, but also encode relations of possession: in (4a) the possessive her signals that the backpack referred to belongs to the referent of the pronoun she, and the possessive its shows that the referent of strap belongs to the mentioned backpack in the sense of being one of its parts. ${ }^{16} \mathrm{Her}$ and its are obligatory markers of these possessive relations: if the markers are not used, the relations are not asserted.

In example (5) the translationally corresponding NPs tekoppen and her tea cup carry inalienability marking although they refer to an alienable concept:

$$
\begin{aligned}
& \text { Hun drakk stadig av tekoppen. }{ }^{17} \\
& \text { 'She drank continually from tea-cup.DEF.' } \\
& \text { She drank continually from her tea cup. }
\end{aligned}
$$

But 'tea cup' is a kind of object typically used by humans, and in the given context these NPs refer to an object that is used by the subject referent, and by nobody else. Because of this close connection between the tea cup and its possessor, the cup is similar to clothing, and the use of inalienability marking is idiomatic in both sentences (5a) and (5b). The example also illustrates the influence of culture-bound factors on alienability splits: in cultures where people do not share items used for drinking and eating it is natural that expressions referring to such objects are marked in the same way as those referring to important personal belongings and to clothes being worn.

\section{Conclusions and questions for further study}

The present article has discussed a translational regularity described by Thunes (2011) as the inalienability pattern of English and Norwegian. It is formally characterised by translational correspondences between English noun phrases premodified by possessive determiners and Norwegian simple definite noun phrases, and it occurs in both directions of translation. The phenomenon exhibits a prototypical structure, where its core cases include inalienable nouns, in

\footnotetext{
14 This example is found in Lessing (1985).

15 The Norwegian suffix -en also marks singular number and common/masculine gender, which are grammatical features of the nouns ryggsekk and skulderrem, respectively.

16 Thus, this is a case where inalienability marking expresses a part-whole relation; cf. section 2.1.

17 This example is found in Vik (1979/1983). Regarding the Norwegian sentence, one could ask whether the NP tekoppen is not simply a case of definite reference. But the referent of tekoppen is not previously introduced in the context from which the sentence is extracted, and since definite form typically signals given information, tekoppen can be seen as an instance of possessor suppression, with the subject referent as the implicit possessor.
} 
particular body part and kinship terms. The non-canonical cases cover alienable nouns, mainly occurring in contexts with human possessors and where the objects are used in a typical way, often involving some kind of close contact between the possessor and the object. The prototypical view of this translational pattern is supported by typological research, and by literature on possession and inalienability.

The English-Norwegian inalienability pattern is a consequence of a systematic difference between the two languages: in English the possession of inalienables is explicitly expressed through obligatory possessor marking, and in Norwegian implicitly through possessor suppression. Thus, the prototypical occurrences of the pattern can be regarded as manifestations of a translational correspondence between rules of English and Norwegian grammar, respectively. This means that in examples such as (1) and (2) the target expressions are linguistically predictable translations, i.e. computable from the information contained in the source expressions together with information about how the two language systems are interrelated (cf. section 2.5).

In relation to the notion of translational complexity (cf. section 3.1), we may observe two points. Firstly, in occurrences of the English-Norwegian inalienability pattern, it is a more complex task to translate from Norwegian into English, than in the opposite direction. The reason is that the English construction, with explicitly encoded possession, provides easier access to information about the possessor relation than the Norwegian construction does. ${ }^{18}$ Moreover, in a given translation task, it is a less complex task to suppress possessor information and generate a simple definite NP in Norwegian, than it is to produce an English NP introduced by a possessive, since the latter involves choosing the correct word form within the set of possessive determiners. Secondly, we may assume that the degree of translational complexity is lower in the prototypical cases of the ialienability pattern than in the non-canonical ones. In the core cases the task of finding the contextually appropriate translation can be solved by using the easily accessible information that the nouns involved denote inalienables, in combination with information about interrelations between the two language systems. Then, in the nonprototypical cases, it may be necessary also to make complex inferences, e.g. in order to find out whether a certain noun denotes an object which is used in a typical way by a human possessor in the given context. With respect to translation into Norwegian, such inferencing may be necessary in order to find out whether possessor information should be suppressed in the target expression, and when translating into English, it is also necessary to derive information about the implicit possessor relation. Thus, there is reason to believe that generating the appropriate English target expressions requires a larger amount of processing effort in the non-canonical instances than in the core cases.

Although occurrences of the inalienability pattern may be infrequent in certain text types, the phenomenon represents an important structural difference between English and Norwegian which must be handled in translation within this language pair. Since the data reported on in Thunes (2011) are limited, it would be interesting to study this translational pattern by compiling corpus data on a larger scale. One possible research question could be whether the direction of translation will influence the frequency of the pattern. That is a pertinent question for at least two reasons. Firstly, we have seen that the direction of translation influences the degree of translational complexity in instances of the inalienability pattern, and, secondly, within the limited data given in Thunes (2011: 371), the inalienability pattern is more frequent in Norwegian-to-English translation than in the opposite direction. Another question is whether a large-scale study could detect differences between kinship and body part terms within occurrences of the pattern. With respect to English, Dahl and Koptjevskaja-Tamm (1998) have pointed out an important difference between the two categories (cf. section 3.2), and regarding Norwegian, Lødrup (2010: 92-98) has shown that there are important differences between,

18 Cf. e.g. the remarks on example (4) in section 3.3. 
respectively, body part and non-body part nouns in terms of syntactic as well as semantic properties. Through a larger empirical study of the English-Norwegian inalienability pattern it could be possible to find out whether kinship and body part nouns differ not only languageinternally, but also with respect to translational properties within this language pair.

\section{Acknowledgements}

I want to thank Helge Lødrup and Maria Koptjevskaja-Tamm for various kinds of helpful input, and Helge Dyvik for insightful comments on an earlier version of this work. Then, it must be said that the present study could not have been undertaken without access to corpus data, and in this respect the author is greatly indebted to the English-Norwegian Parallel Corpus Project, in particular three of its core members: Jarle Ebeling, Knut Hofland, and the late Stig Johansson. By coincidence, I had the luck of working in the office next-door to Knut Hofland during an early stage of the ENPC Project. This pulled my work partly in the direction of contrastive language research undertaken by Stig Johansson and his associates, a field that it was truly a pleasure to be affiliated with. Special thanks are due to Knut Hofland for having been a good colleague for many years, and, not least, for having been such an important part of the backbone of humanities computing in Norway and beyond. 


\section{References}

Barnett, James, Inderjeet Mani, Elaine Rich, Chinatsu Aone, Kevin Knight, and Juan Carlos Martinez. 1991. Capturing Language-Specific Semantic Distinctions in Interlingua-Based MT. In Proceedings of Machine Translation Summit III, 25-32. Washington, DC.

Baron, Irène, Michael Herslund, and Finn Sørensen (eds). 2001. Dimensions of Possession. Typological Studies in Language 47. Amsterdam and Philadelphia: John Benjamins Publishing Company.

Brink, André. 1984. The Wall of the Plague. London: Faber and Faber.

Brink, André. 1984. Pestens mur. Translated by Per Malde. Oslo: H. Aschehoug \& Co (W. Nygaard) AS.

Chappell, Hilary and William McGregor (eds). 1996a. The Grammar of Inalienability. A Typological Perspective on Body Part Terms and the Part-Whole Relation. Empirical Approaches to Language Typology 14. Berlin and New York: Mouton de Gruyter.

Chappell, Hilary and William McGregor. 1996b. Prolegomena to a theory of inalienability. In: Chappell and McGregor (eds), 1996a, 3-30.

Dahl, Östen, and Maria Koptjevskaja-Tamm. 1998. Alienability Splits and the Grammaticalization of Possessive Constructions. In: Haukioja (ed), 1998, 38-49.

Dahl, Östen, and Maria Koptjevskaja-Tamm. 2001. Kinship in grammar. In: Baron et al. (eds), 2001, 201-225.

Dorr, Bonnie J. 1990. Solving thematic divergences in machine translation. In Proceedings of the 28th Annual Meeting of the ACL, 127-134. Pittsburgh, Pennsylvania.

Dyvik, Helge. 1998. A translational basis for semantics. In: Johansson and Oksefjell (eds), 1998, 51-86.

Dyvik, Helge. 1999. On the complexity of translation. In: Hasselgård and Oksefjell (eds), 1999, 215-230.

Faarlund, Jan Terje, Svein Lie, and Kjell Ivar Vannebo. 1997. Norsk referansegrammatikk. Oslo: Universitetsforlaget.

Hansen, Erik Fosnes. 1990. Salme ved reisens slutt. Oslo: J. W. Cappelens Forlag AS.

Hansen, Erik Fosnes. 1996. Psalm at Journey's End. Translated by Joan Tate. New York: Farrar, Straus and Giroux.

Hasselgård, Hilde and Signe Oksefjell (eds). 1999. Out of Corpora. Studies in Honour of Stig Johansson. Language and Computers: Studies in Practical Linguistics 26. Amsterdam and Atlanta, GA: Rodopi.

Haukioja, Timo (ed). 1998. Papers from the 16th Scandinavian Conference of Linguistics. Publications of the Department of Finnish and General Linguistics of the University of Turku 60. University of Turku.

Heine, Bernd. 1997. Possession: Cognitive source, forces, and grammaticalization. Cambridge: Cambridge University Press.

Herslund, Michael and Irène Baron. 2001. Introduction: Dimensions of possession. In: Baron et al. (eds) 2001, 1-25. 
Hofland, Knut and Stig Johansson. 1998. The Translation Corpus Aligner. A program for automatic alignment of parallel text. In: Johansson and Oksefjell (eds), 1998, 87-100.

Johansson, Stig. 1998. On the role of corpora in cross-linguistic research. In: Johansson and Oksefjell (eds), 1998, 3-24.

Johansson, Stig. 2007. Seeing through Multilingual Corpora. On the Use of Corpora in Contrastive Studies. Studies in Corpus Linguistics 26. Amsterdam and Philadelphia: John Benjamins Publishing Company.

Johansson, Stig and Signe Oksefjell (eds). 1998. Corpora and Cross-linguistic Research: Theory, Method, and Case Studies. Language and Computers: Studies in Practical Linguistics 24. Amsterdam and Atlanta, GA: Rodopi.

Johansson, Stig, Jarle Ebeling, and Signe Oksefjell. 1999/2002. English-Norwegian Parallel Corpus: Manual. Department of British and American Studies, University of Oslo.

Jurafsky, Daniel and James H. Martin. 2009. Speech and Language Processing. An Introduction to Natural Language Processing, Computational Linguistics, and Speech Recognition. Second edition. Upper Saddle River, New Jersey: Pearson Education.

Kameyama, Megumi, Ryo Ochitani, and Stanley Peters. 1991. Resolving translation mismatches with information flow. In Proceedings of the 29th Annual Meeting of the ACL, 193-200. Berkeley, California.

Lessing, Doris. 1985. The Good Terrorist. London: Jonathan Cape.

Lessing, Doris. 1985. Den gode terroristen. Translated by Kia Halling. Oslo: Gyldendal Norsk Forlag AS.

Lévy-Bruhl, Lucien. 1914. L'expression de la possession dans les langues mélanésiennes. Mémoire de la Société de Linguistique de Paris 19, 96-104.

Lødrup, Helge. 2010. Implicit possessives and reflexive binding in Norwegian. Transactions of the Philological Society 108:2, 89-109.

McGregor, William B. (ed). 2009a. The Expression of Possession. Berlin and New York: Mouton de Gruyter.

McGregor, William B. 2009b. Introduction. In: McGregor (ed) 2009a, 1-12.

Quirk, Randolph, Sidney Greenbaum, Geoffrey Leech, and Jan Svartvik. 1985. A Comprehensive Grammar of the English Language. London and New York: Longman.

Seiler, Hansjakob. 2001. The operational basis of possession. A dimensional approach revisited. In: Baron et al. (eds), 2001, 27-40.

Thunes, Martha. 2011. Complexity in Translation: An English-Norwegian Study of Two Text Types. Doctoral dissertation. University of Bergen. http://hdl.handle.net/1956/5179

Thunes, Martha. 2012. An analysis of translational complexity in two text types. Translation: Computation, Corpora, Cognition. Special Issue on the Crossroads between Contrastive Linguistics, Translation Studies, and Machine Translation 2:1, 81-101.

Vik, Bjørg. 1979. En håndfull lengsel. Oslo: J. W. Cappelens Forlag AS.

Vik, Bjørg. 1983. Out of Season and Other Stories. Translated by David McDuff and Patrick Browne. London: Sinclair Browne. 